\title{
Severity of a mountain pine beetle outbreak across a range of stand conditions in Fraser Experimental Forest, Colorado, United States
}

Anthony G. Vorster ${ }^{\mathrm{a}^{*}}$, Paul H. Evangelista ${ }^{\mathrm{a}}$, Thomas J. Stohlgren ${ }^{\mathrm{a}}$, Sunil Kumar ${ }^{\mathrm{a}}$, Charles C. Rhoades $^{\mathrm{b}}$, Robert M. Hubbard ${ }^{\mathrm{b}}$, Antony S. Cheng ${ }^{\mathrm{c}, \mathrm{d}}$, and Kelly Elder ${ }^{\mathrm{b}}$

${ }^{a}$ Natural Resource Ecology Laboratory, Colorado State University, Fort Collins, CO, 80523, USA

${ }^{b}$ U.S. Forest Service, Rocky Mountain Research Station, Fort Collins, CO, 80526, USA

${ }^{c}$ Forest and Rangeland Stewardship, Colorado State University, Fort Collins, CO, 80523, USA

${ }^{d}$ Colorado Forest Restoration Institute, Colorado State University, Fort Collins, CO, 80523, USA

* Corresponding author. Address: Natural Resource Ecology Laboratory, A105 NESB, Colorado State University, Fort Collins, CO, 80523-1499, USA Tel.: +1 9704915571 Email address: avorster@ rams.colostate.edu

\begin{abstract}
The recent mountain pine beetle (Dendroctonus ponderosae Hopkins) outbreaks had unprecedented effects on lodgepole pine (Pinus contorta var. latifolia) in western North
\end{abstract} America. We used data from 165 forest inventory plots to analyze stand conditions that regulate lodgepole pine mortality across a wide range of stand structure and species composition at the Fraser Experimental Forest in Colorado, USA. Forest inventory data were then combined with Landsat 7 Enhanced Thematic Mapper Plus (ETM+) imagery and boosted regression trees modeling to map outbreak severity (proportion of basal area killed). The outbreak severity map was evaluated with training (pseudo- $\mathrm{R}^{2}=0.63$, RMSE $=0.13$ ) and independent test plots (pseudo$\mathrm{R}^{2}=0.42$, $\mathrm{RMSE}=0.27$ ). This map was used to compare pine mortality in regenerating clearcuts and mature stands, which would have been problematic otherwise since regenerating clearcuts were underrepresented in the forest inventory data. Mortality spanned from 0-99\% of stand basal area, proportional to the abundance of pine in surveyed stands. During the outbreak, mortality was highest for larger-diameter trees; however, contrary to earlier outbreaks, beetles also attacked younger stands. Pine mortality was lower in stands regenerating from clearcut harvests conducted between 1954 and 1985 than in mature stands and was more closely related to topographic factors than stand age or clearcut size; mortality was highest on southerly aspects 
and lower elevation sites, favorable to lodgepole pine. The best predictors for mapping outbreak severity were the change in the Normalized Difference Moisture Index between pre- and end-ofoutbreak imagery and the end-of-outbreak ETM+ band 5. A better understanding of mortality patterns relative to forest management can inform management planning and assessment of the influence of bark beetle outbreaks on ecosystem processes.

Keywords: boosted regression trees; Dendroctonus ponderosae; Landsat; lodgepole pine; Pinus contorta; remote sensing

\section{Introduction}

Recent mountain pine beetle (Dendroctonus ponderosae Hopkins) outbreaks have caused unprecedented mortality throughout western North American lodgepole pine (Pinus contorta var. latifolia) forests. Mountain pine beetle populations reached epidemic levels in northern Colorado in 2003 coinciding with extreme drought and warm temperatures (Chapman et al., 2012; Tishmack et al., 2005). The outbreak continued to spread until 2010 when populations of live host trees were greatly reduced following years of beetle infestation (Walter and Platt, 2013). The magnitude of the outbreaks across western North America led to novel patterns of pine mortality, including increased mortality in small-diameter trees (Dhar et al., 2015; Maclauchlan et al., 2015) and infestations at higher elevations than were historically susceptible to outbreaks (Sidder et al., 2016; Walter and Platt, 2013). Outbreak severity patterns need to be better understood to quantify the impacts of outbreaks on ecological processes (Diskin et al., 2011; Hansen et al., 2015; Pugh and Small, 2012; Rhoades et al. 2013, 2016). Additionally, management planning to mitigate public safety and address fire concerns, and to enhance 
resilience of forest stands to future outbreaks, would benefit from spatially-explicit information about the patterns of mountain pine beetle outbreak severity and how outbreak severity is influenced by forest management.

Mountain pine beetles attack host trees through pheromone-coordinated mass attacks, where many beetles attack a pine tree simultaneously. Host trees can defend themselves, however, when mountain pine beetle populations are high and/or trees are stressed, the host is killed when blue stain fungi carried by the beetles blocks water transport (Hubbard et al., 2013). A number of studies have demonstrated that host abundance, tree size, and tree density can regulate the severity of mountain pine beetle caused lodgepole pine mortality (Amman et al., 1977; Fettig et al., 2007; Shore and Safranyik, 1992). During outbreaks, mountain pine beetles typically prefer, and have greater reproductive success in, larger, older trees with thicker phloem and bark, and a lower resistance to blue stain fungi (Safranyik and Carroll, 2006; Shrimpton, 1973; Rhoades et al. 2016). Trees less than 60 years old and with diameters under $15 \mathrm{~cm}$ are believed to have lower susceptibility to mountain pine beetle attack (Shore and Safranyik, 1992). However, during the recent outbreaks, trees between 21 and 40 years old with diameters less than $15 \mathrm{~cm}$ diameter were regularly infested (Dhar et al., 2015). Topographic position of a stand also influences susceptibility (Kaiser et al., 2013; Nelson et al., 2014) since species composition and micro-climatic conditions that influence tree vigor and mountain pine beetles vary with topography.

Timber harvesting impacts forest susceptibility to future outbreaks by altering forest structure and species composition. In British Columbia, lodgepole pine mortality declined with decreasing stand age in stands regenerating from clearcut (<60 years old; Dhar et al., 2015; Maclauchlan, 2006; Maclauchlan et al., 2015). Lodgepole pine mortality from mountain pine 
beetles in stands regenerating from clearcut has been minimally studied in the Southern Rocky Mountains. Patch cuts harvested 15-20 years before the end of the recent bark beetle outbreaks in southern Wyoming had lower mortality within and near the cuts (Johnson et al., 2014).

Watersheds at Fraser Experimental Forest in Colorado that experienced extensive historic clearcutting had smaller average tree diameter and lower mountain pine beetle-induced mortality than mature watersheds on average (Rhoades et al., 2016). It is not known how mortality compares between individual mature and regenerating stands older than 20 years old or how characteristics of the clearcut stands (species composition, age, harvest size, and topographic location) relate to outbreak severity. Further study is needed to determine how timber harvesting in past decades interacted with the recent mountain pine beetle outbreak. This can improve understanding of how today's management choices might influence future stand trajectories and insect outbreaks.

Remote sensing provides a historical record and continuous spatial coverage useful for monitoring forest dynamics (Cohen and Goward, 2004). Tree mortality from mountain pine beetles has been effectively mapped using Landsat imagery (e.g., Coops et al., 2010; Goodwin et al., 2008; Meddens and Hicke, 2014; Walter and Platt, 2013). Landsat imagery is particularly suitable for this task because of its 30-m spatial resolution, free availability, spectral resolution, and historical record (Wulder et al., 2012). Maps of cumulative outbreak severity (red and grey attack stage) representing the range of mortality can help improve understanding of how bark beetle outbreaks alter ecosystem processes (Edburg et al., 2012; Ghimire et al., 2015; Pfeifer et al., 2011). Several studies have mapped cumulative outbreak severity using Landsat imagery (Bright et al., 2014; Long and Lawrence, 2016; Simard et al., 2012). These studies used a variety of approaches: single-date (Long and Lawrence, 2016), image differencing across 
multiple dates (Simard et al., 2012), and time-series (Bright et al., 2014). Efforts to map mountain pine beetle activity often rely on moisture-sensitive indices such as the Normalized Difference Moisture Index (NDMI; Coops et al., 2010; Goodwin et al., 2008; Walter and Platt, 2013) and the Tasseled Cap Transformation (Skakun et al., 2003; Wulder et al., 2006) to detect reduced foliar moisture content in dead, beetle-infested trees.

In this study, we combined forest inventory data and remote sensing techniques to investigate mountain pine beetle-induced lodgepole pine mortality patterns across a wide range of stand structure, species composition, and management histories at Fraser Experimental Forest, Colorado, USA. Our objectives were to: (1) identify stand characteristics most related to outbreak severity in stands with lodgepole pine using forest inventory data; (2) map outbreak severity; (3) compare tree mortality between regenerating forests in historic clearcut areas and mature forests; and (4) evaluate how clearcut characteristics (age, size, and topographic location) may regulate mountain pine beetle-induced tree mortality.

\section{Data and Methods}

\subsection{Study Area and Stand Delineation}

Our study area was in the United States Department of Agriculture (USDA) Forest Service Fraser Experimental Forest. Established in 1937, the Fraser Experimental Forest is located in the Rocky Mountains (Figure 1) approximately $81 \mathrm{~km}$ west of Denver, Colorado (Popovich et al., 1993). Elevations within the $93 \mathrm{~km}^{2}$ area range from 2,674 to 3,947 $\mathrm{m}$ while mean monthly temperatures range from $-10^{\circ} \mathrm{C}$ in January to $13^{\circ} \mathrm{C}$ in July. The mean annual precipitation at Fraser Experimental Forest is $740 \mathrm{~mm}$ with two-thirds falling as snow between October and May (Popovich et al., 1993). The vegetation is typical of Colorado subalpine and 
alpine zones and has vegetation communities also found in the mountains of Utah, Wyoming, Montana, and Idaho (Huckaby and Moir, 1998). Lower elevations (2,674 to 3,300 m) and southern aspects are dominated by lodgepole pine forests. Mixed forests of Engelmann spruce (Picea engelmannii), sub-alpine fir (Abies lasiocarpa), and lodgepole pine are found along the valley bottom and north-facing slopes up to the treeline $(3,300$ to $3,500 \mathrm{~m})$, with spruce and fir becoming more dominant as stands age, along streams, and at higher elevations (Popovich et al., 1993). Small stands of quaking aspen (Populus tremuloides) are interspersed throughout lower elevations. Old-growth stands range from 200 to 600 years old, while younger, second-growth lodgepole pine stands that originated after fire and logging in the early twentieth century are widespread in the northern portion of the forest (Alexander, 1987; Popovich et al., 1993).
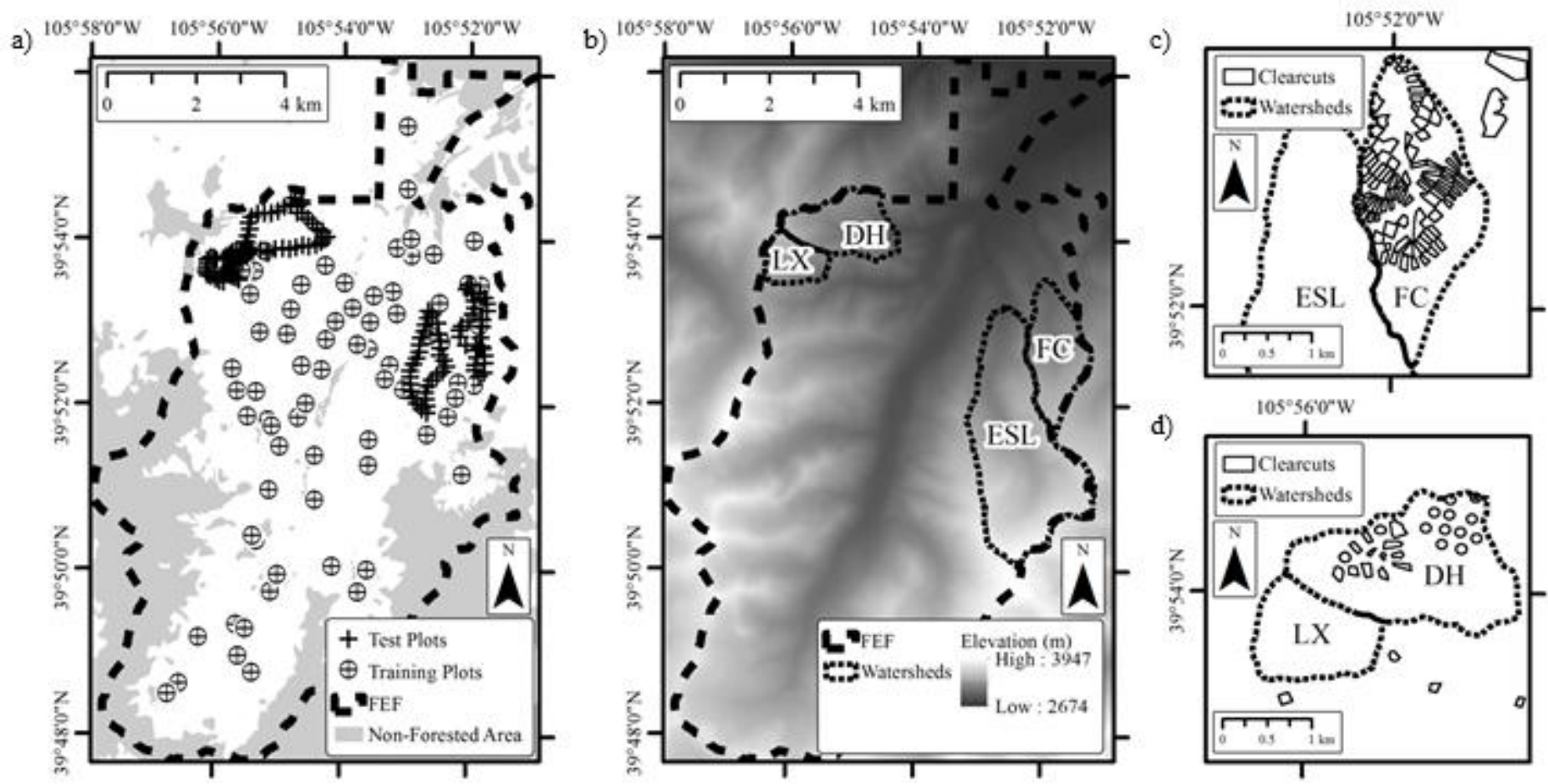

Figure 1. (a) Map of Fraser Experimental Forest (FEF) in Colorado showing the location of field plots and non-forested area. (b) Map showing elevation and the four watersheds discussed in this study. Smaller panes show the regenerating clearcuts in and around the (c) Fool Creek watershed 
(FC) and (d) Deadhorse Creek watershed (DH). LX = Lexen Creek watershed; ESL = East Saint Louis Creek watershed

Lodgepole pine mortality from mountain pine beetles was first noted at the Fraser Experimental Forest in 2003 and became widespread by 2006 (Hubbard et al., 2013; Tishmack et al., 2005). New mountain pine beetle infestations declined sharply in 2010 (Walter and Platt, 2013), and by 2011 there was little mountain pine beetle activity observed at Fraser Experimental Forest (USDA Forest Service, 2013). The outbreak at Fraser Experimental Forest killed $90 \%$ of lodgepole pine with diameters greater than $30 \mathrm{~cm}$, while $90 \%$ of trees with diameters less than $15 \mathrm{~cm}$ survived (Rhoades et al., 2016). The range of lodgepole pine abundance (Huckaby and Moir, 1998) and patchwork of timber harvests (Alexander et al., 1985) at Fraser Experimental Forest are ideal for analyzing recent outbreak patterns.

Clear cutting was conducted between 1954 and 1985 in the study area as part of various research projects (Alexander et al., 1985; Troendle and King, 1985). Stands regenerating from the harvests were between 25 and 56 years old by the end of the recent mountain pine beetle outbreak. The location and age of regenerating clearcuts were collected from published reports (Alexander et al., 1985), aerial photographs (USDA Forest Service), the National Aerial Photography Program (USGS EROS Data Center), National Agriculture Imagery Program (NAIP; USDA Farm Service Agency), and US Forest Service personnel (W. Shepperd, personal communication, May 15, 2014). Stands regenerating from clearcut were delineated in a geographic information system (GIS; Exelis Visual Information Solutions, 2014). The majority of the regenerating clearcuts used in this study were located in the Fool Creek and Deadhorse Creek watersheds (Figure 1; Table 1). Two regenerating clearcuts just outside of Fraser 
Experimental Forest were included in this analysis. The age of most clearcuts was accurate within one or two years, but seven clearcuts were aged from the first year visible in aerial imagery with a seven-year gap between images. Small treatments $(<30 \mathrm{~m}$ wide) were not delineated because geometric registration and spatial resolution of Landsat combined with potential harvest delineation errors would compromise the accuracy of analysis. Harvests were not included as a regenerating clearcut, but were excluded from mature forest, if they were not a clearcut (i.e., a partial cut), the age uncertainty exceeded seven years, or were harvested outside the time frame of interest. We know of about 34 ha of harvested areas reported by Alexander et al. (1985) that we were unable to locate.

Table 1. Summary of the age, size, and width of regenerating clearcuts delineated in this study at Fraser Experimental Forest. Width is the least dimension of a minimum rectangle fit to the each regenerating clearcut polygon. $\mathrm{SD}=$ standard deviation

\begin{tabular}{|c|c|c|c|c|c|c|c|c|c|c|c|c|}
\hline & \multirow[b]{2}{*}{$\mathrm{n}$} & \multirow[b]{2}{*}{ Years Cut } & \multicolumn{6}{|c|}{ Area (ha) } & \multicolumn{4}{|c|}{ Width (m) } \\
\hline & & & Mean & SD & Min & Max & $\begin{array}{c}\text { Sum of } \\
\text { Harvests }\end{array}$ & Watershed & Mean & SD & Min & Max \\
\hline $\begin{array}{l}\text { Fool } \\
\text { Creek }\end{array}$ & 80 & $1954-1956$ & 0.9 & 0.6 & 0.1 & 3.5 & 71.9 & 298 & 73 & 32 & 34 & 203 \\
\hline $\begin{array}{c}\text { Deadhorse } \\
\text { Creek }\end{array}$ & 25 & $\begin{array}{l}1977-1978 \\
1982-1984\end{array}$ & 1.0 & 0.4 & 0.3 & 2.3 & 24.2 & 273 & 94 & 23 & 46 & 157 \\
\hline All Cuts & 115 & 1954-1985 & 1.2 & 1.7 & 0.1 & 13.0 & 141.8 & N/A & 86 & 45 & 34 & 300 \\
\hline
\end{tabular}

We delineated mature forests to compare to regenerating clearcuts (Supplementary material S.1). Mature forests excluded the regenerating clearcuts, harvested areas that were not included as a regenerating clearcut for the aforementioned reasons, and the entire Fool Creek watershed. The Fool Creek watershed is a complex matrix of small cut and uncut stands that cannot be confidently labeled as free of influence from harvesting. We also excluded a $30 \mathrm{~m}$ 
buffer around each clearcut to account for edge effects, such as blow down (Alexander et al., 1985) and altered bark beetle susceptibility (Johnson et al., 2014).

We delimited non-forested areas using a maximum likelihood supervised classification to remove from our analysis (Exelis Visual Information Solutions, 2014). Polygons derived from visual inspection of NAIP imagery trained the classification. We then manually edited the nonforested extent to better match the extent observed in aerial imagery. Areas identified as being harvested since 2000 using NAIP imagery were also excluded from the mountain pine beetle outbreak severity map.

\subsection{Forest Inventory Data}

Forest inventory data were used to examine stand-scale, mountain pine beetle-induced lodgepole pine mortality, and to train a boosted regression trees (BRT) outbreak severity model. In 2008, we randomly selected 73 sample sites (Figure 1). In each 17.9-m fixed-radius plot, we recorded species, diameter at breast height $(\mathrm{DBH})$, and status (canopy class or dead) for each tree larger than $2 \mathrm{~cm} \mathrm{DBH}$. Trees between 2 and $2.5 \mathrm{~cm}$ DBH were excluded to match the minimum diameter measured in the second field dataset introduced below. Of the 73 sample plots, 48 plots had lodgepole pine but little bark beetle activity in 2008. We re-measured these 48 plots in 2012 and 2013 to monitor further mountain pine beetle-induced mortality. The remaining 25 plots were either dominated by subalpine fir and Engelmann spruce or the lodgepole pine in the plot had already suffered high mortality in 2008. Hereafter, the 48 plots revisited in 2012 and 2013 and the remaining 25 plots will be referred to as the training data $(n=73)$.

We used an independent set of field data (Rhoades et al. 2016) to examine relationships between stand conditions and mountain pine beetle-induced tree mortality and as test data to 
validate our BRT outbreak severity model. The test data consisted of 133, 10-m radius plots inventoried in 2007 to record species, DBH, status (crown class or dead), and year of mountain pine beetle caused mortality for each tree $>2.5 \mathrm{~cm}$. An average of 33 plots are organized in a looping pattern across four research watersheds, spaced an average of $141 \mathrm{~m}$ apart in Deadhorse Creek, 159 m apart in East Saint Louis Creek, 162 m apart in Fool Creek, and 83 m apart in Lexen Creek. The test data are the same plots used in Rhoades et al. (2016), but we summarized the data differently and we incorporated changes in tree status documented in 2011. While our forest composition trends are similar to those reported in Rhoades et al. (2016), the values differ because our study did not disaggregate trees into overstory and subancopy groups and we included a second set of forest inventory plots (the training plots). Additionally, our study classified plots as mature or regenerating clearcut, while Rhoades et al. (2016) summarized plots by mature and mixed-age watershed averages.

Only 10 forest inventory plots fell within regenerating clearcuts and these were not representative of the range of regenerating clearcut stand structures. As such, we mapped outbreak severity to address Objectives 3 and 4 . These 10 plots were, however, used to characterize the stand structure and accuracy of outbreak severity predictions in regenerating clearcuts. Three of these plots were training plots and seven were test plots.

We calculated the ratio of dead lodgepole pine basal area to the basal area of all live and dead trees of all species as an index of mountain pine beetle outbreak severity. This index reflects the relative abundance of lodgepole pine and the proportional mortality of pine within a stand and is well correlated to ecosystem responses and forest recovery from bark beetles (Hubbard et al. 2013; Rhoades et al. 2016). The use of this index as a measure of mountain pine beetle-caused impacts assumes that all lodgepole pine mortality was a result of mountain pine 
beetles; we found that $76 \%$ of dead lodgepole pine in the test plots had signs of mountain pine beetle attack. Outbreak severity ranged from 0 to 0.82 in the training plots $(\mathrm{mean}=0.28$, $\mathrm{SD}=0.26$ ), and from 0 to 0.99 in the test plots (mean=0.35, $\mathrm{SD}=0.32$ ). A non-parametric equivalence test indicated that outbreak severity for the two datasets originate from the same population ( $\mathrm{p}<0.01$; R Core Team, 2015; Robinson, 2015).

\subsection{GIS and Remote Sensing Data}

Many predictor variables for the models used to map outbreak severity and to assess mortality patterns in lodgepole pine stands and regenerating clearcuts were derived from GIS and remote sensing data (Table 2). We obtained elevation, slope, and aspect for each plot and each regenerating clearcut polygon from a digital elevation model (DEM) acquired from the USGS National Elevation Dataset (Gesch et al., 2002; Gesch, 2007). We converted aspect from a circular scale (degrees) to a linear north-south (northness) and east-west (eastness) gradient (Kumar et al., 2006). Once converted, aspect is defined by two values ranging from -1 (south or west) to 1 (north or east).

We used Landsat ETM+ images (path 34, row 32) from September 24, 2001 and September 17, 2010 to represent conditions before and at the end of the outbreak. September images feature stable plant phenology and they allow sufficient time for mountain pine beetlekilled trees to fade after the previous year's attack (Goodwin et al., 2008). Cloudless Landsat 7

ETM+ Climate Data Record (CDR) surface reflectance images were downloaded from the USGS Earth Explorer website (http://earthexplorer.usgs.gov/). We excluded a 5.4-ha area of the East Saint Louis Creek watershed that is impacted by the ETM+ Scan Line Corrector failure in the 2010 image. 
We used the Landsat CDR surface reflectance product to account for sensor, solar, and atmospheric differences between image captures in the visible and shortwave infrared bands. Landsat CDR images are Level $1 \mathrm{~T}$ images that have been converted to surface reflectance using the Landsat Ecosystem Disturbance Adaptive Processing System (LEDAPS; Masek et al., 2006). Visual assessment confirmed the satisfactory geometric registration reported in the image metadata (2001 image root mean square error $[\mathrm{RMSE}]=3.2 \mathrm{~m} ; 2010$ image RMSE=4.2 m). The images were then topographically corrected using the Minnaert correction to account for topographic effects on illumination (Leutner and Horning, 2015; R Core Team, 2015; Riaño et al., 2003; Vanonckelen et al., 2013). We converted the thermal band (ETM+ Band 6) from digital number to brightness temperature ( ${ }^{\mathrm{O}}$ Kelvin; Exelis Visual Information Solutions, 2014).

Predictor variables used for the BRT model to map outbreak severity were generated from the preprocessed ETM+ images (Table 2). All calculation of indices and image differencing was completed in R Statistical Package (Bivand et al., 2015; Hijmans, 2015; Leutner and Horning, 2015; R Core Team, 2015). We calculated three Tasseled Cap bands (brightness, greenness, and wetness) from images calibrated to top-of-atmosphere reflectance (Crist and Cicone, 1984; Huang et al., 2002). All pre (2001) and end-of-outbreak (2010) layers (Landsat ETM+ bands, NDMI, and Tasseled Cap bands) were differenced to highlight mountain pine beetle-induced mortality. We extracted values from each differenced layer and the 2010 layers at training and test plot locations using bilinear sampling to mitigate potential effects of misalignment between plots and satellite imagery.

\subsection{Statistical Analyses}

\subsubsection{Regression Trees}


Regression tree analyses were used to identify stand attributes most related to outbreak severity in (1) training and test plots with lodgepole pine $(n=165)$ and (2) stands regenerating after clearcut harvests (Table 2). We chose regression trees for their ease of use and interpretation. Regression trees model relationships between response and predictor variables using repeated binary splits in the data that reduce in-group variability (Breiman et al., 1984).

The first regression tree modeled the relationship between outbreak severity calculated from forest inventory data and the following predictor variables from forest inventory and GIS data: lodgepole pine and total quadratic mean diameter (QMD), lodgepole pine and total density (number of stems and basal area), slope, eastness, northness, and elevation. The second regression tree used the average outbreak severity within each regenerating clearcut polygon derived from the outbreak severity map (section 2.4.2) and the age, area, width (narrowest dimension of the stand), slope, eastness, northness, and elevation of each regenerating clearcut as predictor variables. Regression tree analyses were conducted using the Recursive Partitioning and Regression Trees (rpart) package (R Core Team, 2015; Therneau et al., 2015). Regression trees were pruned to avoid over-fitting. We identified the best complexity parameter for pruning using cross-validation (Therneau and Atkinson, 2011).

\subsubsection{Boosted Regression Trees}

We used boosted regression trees (BRT) to model the relationship between outbreak severity in the training plots and remotely-sensed predictor variables (Table 2). The BRT was then applied to the predictor variable raster layers to map outbreak severity. The combination of regression trees and boosting creates a model that can use a variety of predictor variable types, handles complex interactions, and predicts new observations well (De'ath, 2007; Elith et al., 2008). Boosting builds many regression trees in an ordered fashion that increases emphasis on 
poorly modeled observations (Elith et al., 2008). We used code modified from Elith et al. (2008) to implement the BRT (R Core Team, 2015; Ridgeway et al., 2015). A learning rate of 0.0025 , tree complexity of 3 , and a bag fraction of 0.5 maximized model performance and yielded a model of 1,400 trees (Elith et al., 2008). The Landsat predictor variables previously discussed and slope, eastness, northness, and elevation were used as predictor variables. We kept one predictor variable from each group of variables with a Pearson correlation of \pm 0.70 or more (Dormann et al., 2013), keeping the variable expected to have the highest predictive power in the final model based on the literature and variable importance in exploratory model runs. We prioritized the removal of predictor variables highly correlated with multiple variables over those correlated with a single variable. Variables that were dropped due to multicollinearity include 2010 NDMI, 2010 Tasseled Cap wetness, Tasseled Cap wetness difference, and ETM+ band 5 difference. Further, we iteratively fit models with the least important predictor variable removed and reassessed predictive performance using 10-fold cross-validation. This process identified poorly-performing predictor variables to remove to arrive at a simple model with maximized predictive performance (Elith et al., 2008). Relative importance of predictors was evaluated by averaging the predictor variables' influence across all trees (Friedman, 2001). We evaluated model performance by calculating the coefficient of determination (pseudo- $\mathrm{R}^{2}$ ) at the training plots using 10-fold cross-validation and the independent test plots. Root mean square error was also calculated at the training plots and independent test plots. Model performance within regenerating clearcuts was evaluated using the 10 inventory plots falling within regenerating stands.

\section{Results}




\subsection{Stand Structure}

The forest inventory data showed Fraser Experimental Forest has considerably more dead than live lodgepole pine basal area and there is less live lodgepole pine than live Engelmann spruce and subalpine fir (Figure 2). The mountain pine beetle had a disproportionate impact on basal area compared to number of stems, reflecting the mountain pine beetle's preference for larger trees. The quadratic mean diameter was larger for dead lodgepole pine than live lodgepole pine in both mature and regenerating clearcut stands (Figure 3). The relative basal area importance by species was similar between plots in clearcuts $(n=10)$ and mature forests $(n=156$; Figure 3). Comparisons between outbreak severity in regenerating clearcuts and mature watersheds may be most appropriate between Deadhorse Creek and Lexen Creek watersheds since their stand structures are very similar, while the East Saint Louis Creek and Fool Creek watersheds are less similar (Figure 2).

a)

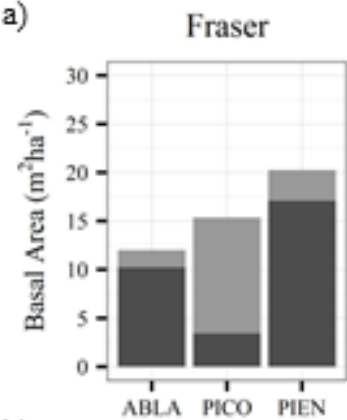

b)

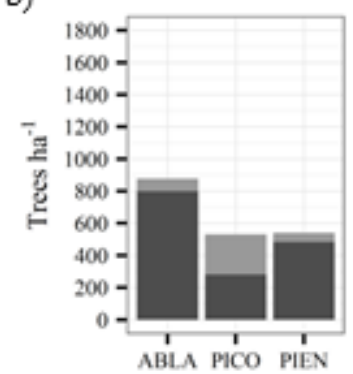

Fool Creek
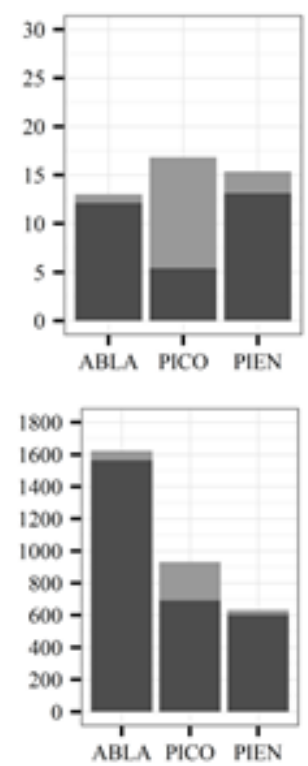

East Saint Louis
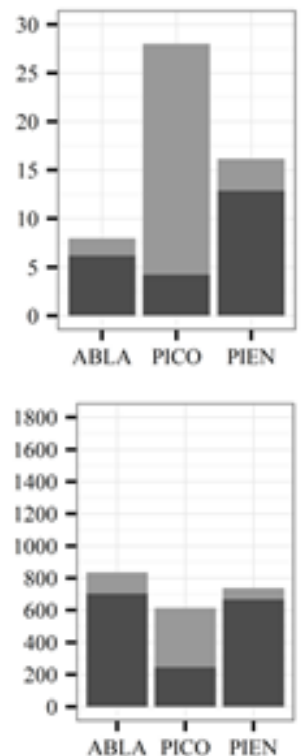

Deadhorse
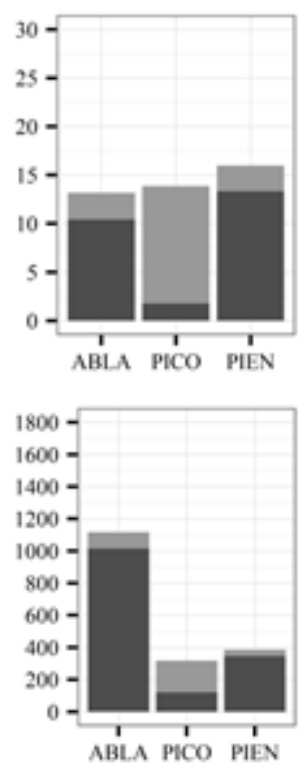

Lexen
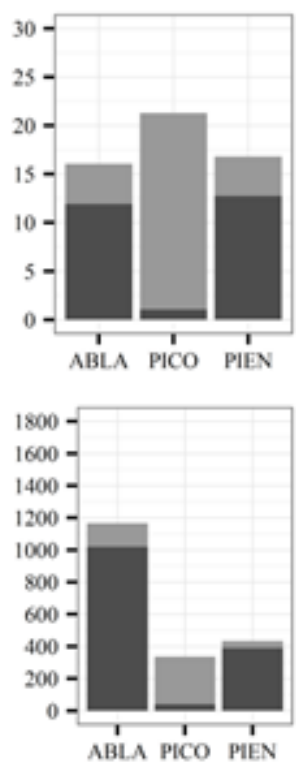

Figure 2. Live and dead (a) basal area and (b) number of trees greater than $2.5 \mathrm{~cm}$ diameter in Fraser Experimental Forest and in four watersheds within Fraser Experimental Forest. The Fraser 
Experimental Forest panes were created from the training plots ( $\mathrm{n}=73,17.9-\mathrm{m}$ plot radius), and the information for each watershed was based on the test plots ( $\mathrm{n}=133,10-\mathrm{m}$ plot radius) within the respective watershed. $\mathrm{ABLA}=$ Abies lasiocarp $; \mathrm{PICO}=$ Pinus contorta $; \mathrm{PIEN}=$ Picea engelmannii
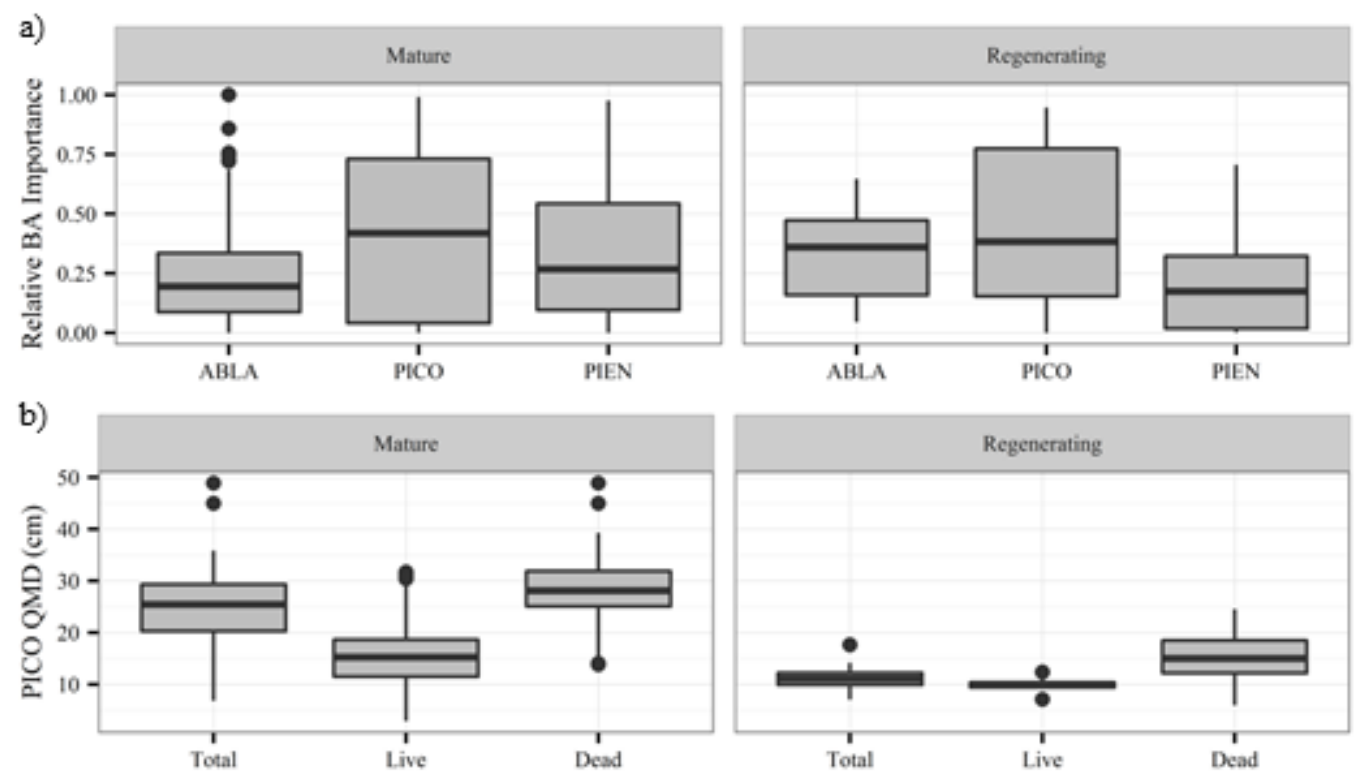

Figure 3. Boxplots of (a) relative basal area (BA) importance of Abies lasiocarpa (ABLA), Pinus contorta (PICO), and Picea engelmanii.(PIEN) and (b) quadratic mean diameter (QMD) of the total, live, and dead lodgepole pine in mature plots $(\mathrm{n}=156)$ and plots regenerating from clearcut $(n=10)$.

\subsection{Regression Tree of Outbreak Severity in Plots with Lodgepole Pine}

Training and test plots with lodgepole pine had varying density $\left(414-7,378\right.$ trees ha $\left.^{-1}\right)$, QMD (7.2 - $34.9 \mathrm{~cm})$, lodgepole pine relative importance $(0-99 \%$ of basal area), and management history (mature and regenerating clearcut). Lodgepole pine basal area ha ${ }^{-1}$ was the strongest predictor of mountain pine beetle outbreak severity in the regression tree analyzing 
stand conditions that regulate lodgepole pine mortality (Table 2); stands with less than $22 \mathrm{~m}^{2} \mathrm{ha}^{-1}$ of lodgepole pine basal area had an average outbreak severity of 0.19 (Figure 4). The average outbreak severity tripled in stands with more than $22 \mathrm{~m}^{2} \mathrm{ha}^{-1}$ of lodgepole pine basal area. Scatter plots of each predictor used as a split in the regression tree show the strong positive correlation between lodgepole pine basal area and outbreak severity (Supplementary material S.2). Outbreak severity tended to increase with QMD and decrease with trees $\mathrm{ha}^{-1}$. Many predictor variables were not included in the final regression tree: lodgepole pine $\mathrm{ha}^{-1}$, lodgepole pine QMD, basal area $\mathrm{ha}^{-1}$ of all species, elevation, slope, eastness, and northness. Lodgepole pine relative basal area importance was not included in the model because it is highly correlated with lodgepole pine basal area $\mathrm{ha}^{-1}$.

Table 2. Summary of the purpose, structure, and performance of the three models used in this study. The relative importance of predictor variables for the regression trees do not sum to 100 because predictor variables that were pruned are not included in the table. Pseudo- $\mathrm{R}^{2}$ values are reported for the BRT outbreak severity map. BA = basal area; $\mathrm{QMD}=$ quadratic mean diameter; NDMI = Normalized Difference Moisture Index; ETM+ = Enhanced Thematic Mapper Plus; TCAP $=$ Tasseled Cap; $\mathrm{CV}=$ cross-validation

\begin{tabular}{|c|c|c|c|c|c|}
\hline Purpose & $\begin{array}{c}\text { Source of Response } \\
\text { Variable }\end{array}$ & Model & $\begin{array}{c}\text { Predictor Variables (Relative } \\
\text { Importance, } \% \text { ) }\end{array}$ & $\mathbf{R}^{2}$ & RMSE \\
\hline $\begin{array}{l}\text { Assess mortality } \\
\text { across stands with } \\
\text { lodgepole pine }\end{array}$ & $\begin{array}{l}\text { Training and test } \\
\text { plots with lodgepole } \\
\text { pine ( } n=165 \text { plots })\end{array}$ & $\begin{array}{l}\text { Regression } \\
\text { tree }\end{array}$ & $\begin{array}{c}\text { P. contorta } \mathrm{BA} \mathrm{ha}^{-1}(34) \\
\text { QMD of all species }(16) \\
\text { Trees ha } \\
\text { Tre }(12)\end{array}$ & $\begin{array}{c}\text { In-sample }=0.80 \\
C V=0.66\end{array}$ & In-sample $=0.13$ \\
\hline $\begin{array}{l}\text { Map outbreak } \\
\text { severity }\end{array}$ & $\begin{array}{l}\text { Training plots } \\
(\mathrm{n}=73 \text { plots }), \text { test } \\
\text { plots }(\mathrm{n}=133) \text { for } \\
\quad \text { validation }\end{array}$ & $\begin{array}{l}\text { Boosted } \\
\text { regression } \\
\text { trees }(\mathrm{BRT})\end{array}$ & $\begin{array}{c}\text { NDMI difference (49) } \\
\text { ETM+ band } 52010(24) \\
\text { Thermal band difference (16) } \\
\text { TCAP brightness difference (11) }\end{array}$ & $\begin{array}{c}\mathrm{CV}=0.63 \\
\text { Test plots }=0.42\end{array}$ & $\begin{array}{l}\text { In-sample }=0.13 \\
\text { Test plots }=0.27\end{array}$ \\
\hline $\begin{array}{l}\text { Assess mortality } \\
\text { across } \\
\text { regenerating } \\
\text { clearcuts }\end{array}$ & $\begin{array}{l}\text { Outbreak severity } \\
\text { (from map) in } \\
\text { regenerating } \\
\text { clearcuts } \\
\text { (n=115 stands) }\end{array}$ & $\begin{array}{l}\text { Regression } \\
\text { tree }\end{array}$ & $\begin{array}{l}\text { Northness }(25) \\
\text { Elevation }(20)\end{array}$ & $\begin{array}{c}\text { In-sample }=0.64 \\
\mathrm{CV}=0.52\end{array}$ & In-sample $=0.07$ \\
\hline
\end{tabular}




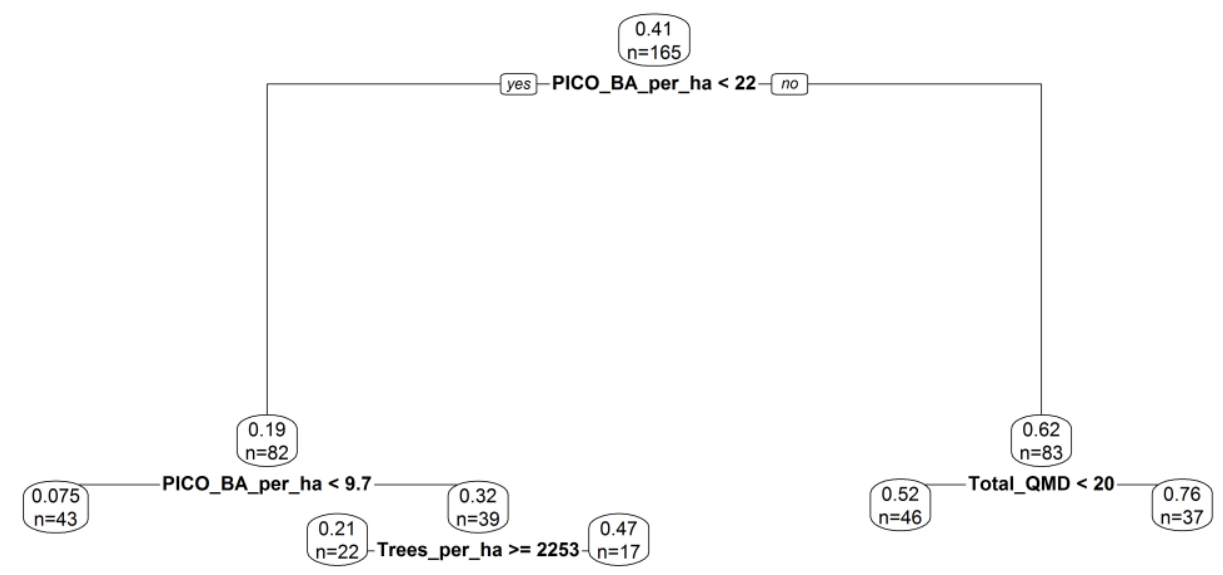

Figure 4. Regression tree showing the relationship between stand structure and mountain pine beetle outbreak severity in all test and training plots containing lodgepole pine (PICO). The height of each branch is proportional to the strength of each split. The text in the box at each node shows the average outbreak severity of each plot within the node and the number of plots (n) in the node. $\mathrm{BA}=$ basal area $\left(\mathrm{m}^{2} \mathrm{ha}^{-1}\right) ; \mathrm{QMD}=$ quadratic mean diameter $(\mathrm{cm})$

\subsection{Outbreak Severity Map}

The BRT model performance was stronger when evaluated with training data than with the test data (Table 2). Ten training and test plots that fell within harvested areas were used to test BRT model performance in harvested stands (pseudo- $\left.\mathrm{R}^{2}=0.65, \mathrm{RMSE}=0.12\right)$. The model was simplified to four predictor variables because increasing the number of predictor variables complicated the model without increasing predictive power. The NDMI difference between 2001 and 2010 was the most important predictor variable (Table 2). In general, as the NDMI difference and ETM+ Band 5 reflectance increased, outbreak severity increased (Supplementary 
material S.3). The outbreak severity map ranged in the ratio of dead lodgepole pine basal area to total basal area from -0.03 to 0.63 (Figure 5). The model tended to under-predict outbreak severity (Supplementary material S.4). The maximum predicted value of 0.63 was lower than the outbreak severity calculated at nine of the training data plots and 31 test data plots.
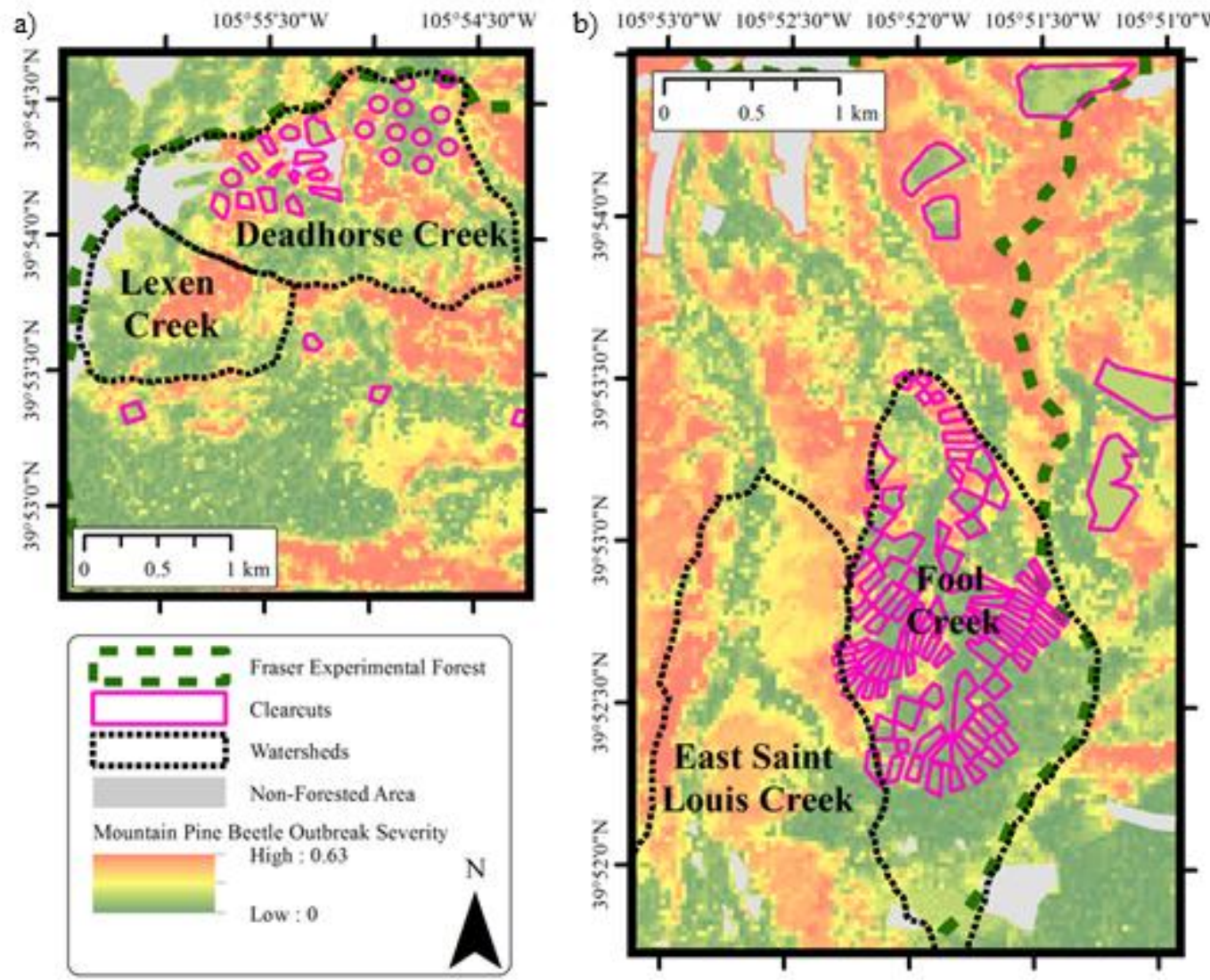

Figure 5. Regenerating clearcuts and predicted outbreak severity by the boosted regression trees model in (a) Deadhorse Creek and Lexen Creek watersheds and in (b) Fool Creek and East Saint Louis Creek watersheds.

\subsection{Outbreak Severity in Regenerating Clearcuts and Mature Forest}

The outbreak severity map showed that the average outbreak severity in young stands regenerating from clearcuts was $0.14(\mathrm{SD}=0.12)$, compared to an average of $0.23(\mathrm{SD}=0.23)$ in 
mature areas. Regenerating clearcuts in the Fool Creek and Deadhorse Creek watersheds had lower outbreak severity than the control watersheds (Figure 6). Although there are only 10 plots that fall within regenerating clearcuts, these plots had lower outbreak severity than plots in mature areas (Figure 6). The lower outbreak severity in many regenerating clearcuts was visible on the outbreak severity map as pockets of low severity surrounded by higher severity areas (Figure 5). While the regenerating clearcuts had less lodgepole pine mortality as a whole, these young stands still had mortality (Figure 6). Outbreak severity was as high as 0.56 and 0.31 in stands regenerating from clearcuts completed 54 and 26 years before the end of the outbreak, respectively. The average outbreak severity of the mature forest is most likely underestimated since recent harvesting targeted stands severely impacted by mountain pine beetle and were excluded from this study.

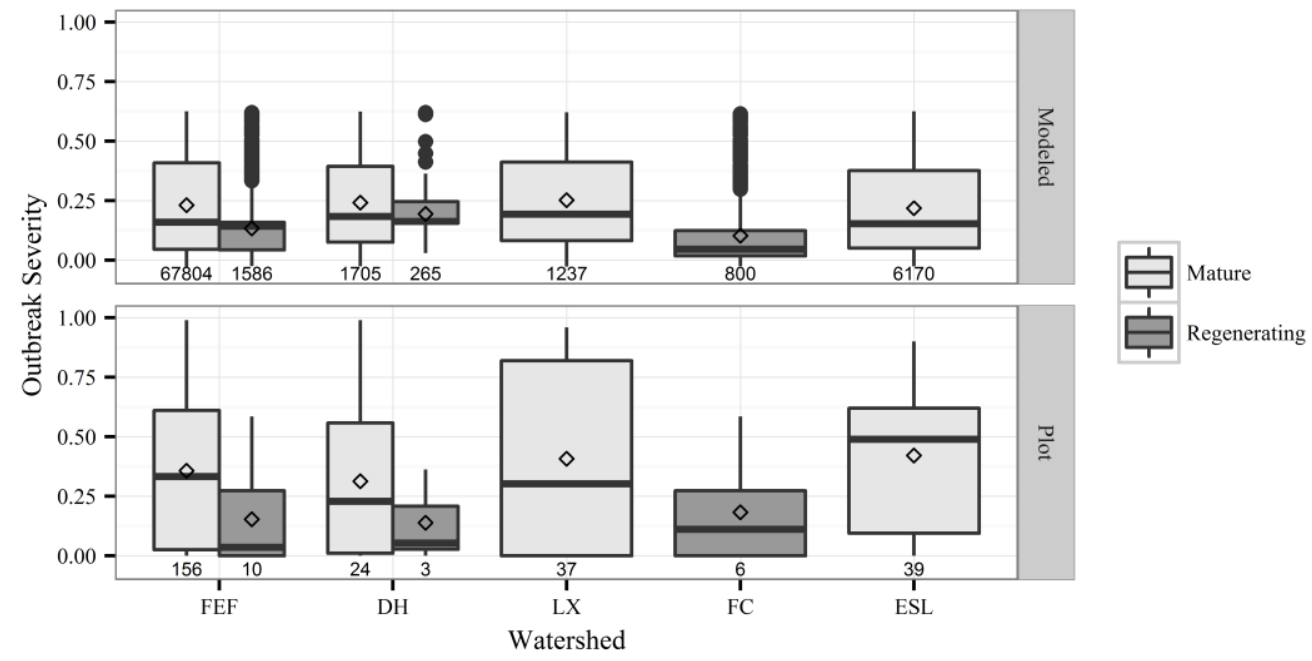

Figure 6. A comparison of outbreak severity between regenerating clearcuts and mature forests across Fraser Experimental Forest (FEF) and in the Deadhorse Creek (DH), Lexen Creek (LX), Fool Creek (FC), and East Saint Louis Creek (ESL) watersheds. The modeled outbreak severity is the outbreak severity predicted by the boosted regression trees model at all pixels within the respective area. The Lexen Creek watershed and East Saint Louis Creek watersheds serve as 
controls (no cutting) for the Deadhorse Creek watershed and Fool Creek watershed, respectively. Outbreak severity of mature forests in Fool Creek is not shown because it is difficult to identify stands not impacted by harvesting. Outbreak severity was measured as a ratio of dead lodgepole pine basal area to total basal area. The values below each boxplot show the number of pixels (top pane) or number of plots (bottom pane). Diamonds are the means.

Northness explained the most variation in the regression tree analyzing outbreak severity in stands regenerating by clearcut (Figure 7; Table 2). Regenerating clearcuts on more northfacing aspects had lower outbreak severity, while those on more southerly aspects and at elevations below 3,017 m experienced the highest mortality. The age, area, width, slope, and eastness of regenerating clearcuts were not important predictors of mountain pine beetle outbreak severity.

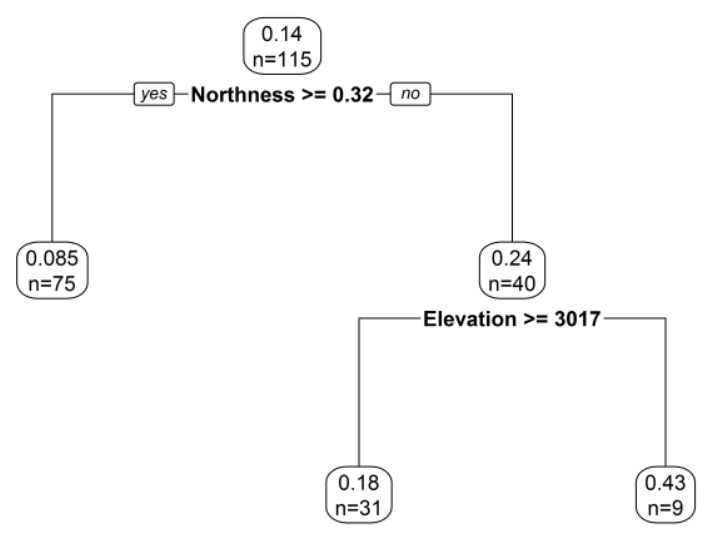

Figure 7. Regression tree showing the relationships between outbreak severity in regenerating clearcuts and clearcut attributes. The text at each node tells the average outbreak severity of the regenerating clearcuts at each node, the number (n) of stands regenerating by clearcut in each 
node, and the predictor variable split separating the next lower pair of nodes. The height of a branch is proportional to the strength of each split.

\section{Discussion}

\subsection{Outbreak Severity across a Range of Stand Conditions}

Lodgepole pine abundance (absolute basal area) was the most important predictor of outbreak severity during the recent mountain pine beetle outbreak across stands with a range of stand structures, pine relative abundances and management histories at Fraser Experimental Forest. These findings are consistent with other studies conducted in northern Colorado reporting that mountain pine beetles attacked stands with abundant lodgepole pine (Klutsch et al., 2009; Nelson et al., 2014; Walter and Platt, 2013) and that the outbreak continued until there were not enough host trees to support the mountain pine beetle population (Meddens and Hicke, 2014; Walter and Platt, 2013). Quadratic mean diameter and stand density of all species also influenced outbreak severity, but the influence was much less than that of lodgepole pine abundance (Figure 4). The preference of mountain pine beetles for larger trees is well-documented on the same test plots at Fraser Experimental Forest (Rhoades et al., 2016). During historical outbreaks, stand density (trees ha ${ }^{-1}$ ) was an important predictor of stand susceptibility (Bartos and Ammman, 1989; Shore and Safranyik, 1992), however density was only of minor importance at Fraser Experimental Forest during the recent outbreak. We analyzed outbreak patterns at the end of the outbreak and conditions associated with pine mortality can change throughout an outbreak (Nelson et al., 2014; Walter and Platt, 2013); other variables may have been important earlier in the outbreak. The mountain pine beetle population surpassed tree and stand-scale thresholds due to suitable climatic and forest structure conditions to become a landscape-level eruption (Raffa et 
al., 2008). When this occurs, controls on previous thresholds such as tree density and age become less important and evidence of their potential importance earlier in the outbreak is obfuscated (Raffa et al., 2008).

\subsection{Harvested Stands were Less Susceptible to Outbreaks}

Forests regenerating by clearcuts completed between 1954 and 1985 had smaller diameter trees and lower outbreak severity than mature stands (Figures 3 and 6). Rhoades et al. (2016) found that the mixed-age watersheds (Fool Creek and Deadhorse Creek) have smaller mean diameter, different species composition and lower mountain pine beetle-induced mortality than mature watersheds (East Saint Louis Creek and Lexen Creek) at Fraser Experimental Forest. Our study builds on their work by mapping outbreak severity to analyze just the harvested stands rather than entire watersheds with mixed management histories. Historically, stands less than 60 years old were not considered susceptible to mountain pine beetle outbreaks (Shore and Safranyik, 1992), however, in this study, some 26 year old stands experienced $>30 \%$ basal area mortality and some 54 year old stands experienced $>50 \%$ mortality. Increased mortality in young stands relative to previous outbreaks has also been observed by studies in British Columbia (Dhar et al., 2015; Maclauchlan et al., 2015). The average dead lodgepole pine tree in regenerating clearcuts was larger $(15.3 \mathrm{~cm}$ diameter) than the surviving pine $(9.7 \mathrm{~cm})$, indicating that mountain pine beetles attacked the largest trees in these young stands. Secondary bark beetles can also cause mortality in young stands, although Maclauchlan et al., (2015) found this to be much less than MPB-induced mortality. Managing to maintain a diversity of tree age classes on the landscape increases resistance and resilience to bark beetle disturbances through reduced mortality in the young stands and potentially in the immediately surrounding mature 
forests (Johnson et al., 2014) and the rapid compensatory growth of young trees in response to overstory mortality (Rhoades et al, 2016). Young stands with lower mortality may also serve as refugia for wildlife (Johnson et al., 2015) and sustain live growing stocks.

The regression tree relating outbreak severity to regenerating clearcut attributes showed that regenerating clearcuts on sites favorable to lodgepole pine (southerly aspects and lower elevations) had the highest levels of mortality (Figure 7). This pattern is most likely driven by the topographic factors that regulate lodgepole pine distribution and abundance in both the regenerating clearcut and the surrounding mature stands. Topographic positions with more mature lodgepole pine likely exerted stronger beetle pressure on nearby regenerating clearcuts. While host resistance and beetle development are also impacted by conditions that vary with elevation and aspect such as water availability, temperature, insolation and evapotranspiration rates (Chapman et al. 2012; Kaiser et al., 2013), host resistance and beetle development are unlikely to have driven these outbreak patterns since the thresholds that these factors control were surpassed during the recent outbreak (Raffa et al., 2008). Topographic factors correlated with host distribution drove outbreak severity patterns in young stands at Fraser Experimental Forest rather than stand age and area. Clearcut age may have been a more influential predictor of outbreak severity if a broader range of stand ages and aspect combinations were studied.

\subsection{Mapping Outbreak Severity}

We mapped mountain pine beetle outbreak severity to assess tree mortality across regenerating clearcuts and mature stands using a combination of inventory data, Landsat ETM+ imagery, and a BRT model. Our model performed reasonably well across Fraser Experimental Forest but generally under-predicted the ratio of dead lodgepole pine basal area to total basal 
area. Under-prediction of outbreak severity could be due to the inclusion of only dead lodgepole pine basal area (excluding all other species) in the response variable numerator despite the detection of needle moisture loss in other species, such as dead spruce and fir trees, by the Landsat predictor variables. By training the model to exclude mortality from the species that experienced minor mortality compared to lodgepole pine, the model could have ignored some of the signal of dead lodgepole pine as well. When evaluated using cross-validation, our model performed similarly to other efforts to map cumulative outbreak severity (Long and Lawrence, 2016; Simard et al., 2012). However, model performance was lower when validated with the test data than it was using cross-validation, partially because the test data had a broader range (0$0.99)$ of outbreak severity than the training plots $(0-0.82)$. The test data validation should be interpreted as the model performance within the Fool Creek, East Saint Louis Creek, Deadhorse Creek, and Lexen Creek watersheds since the test plots were clustered in these watersheds.

Two measures of vegetation moisture, the NDMI difference between 2001 and 2010 and 2010 ETM+ Band 5, were the most influential predictor variables in our BRT model (Table 2).

Other studies have also found that the spectral signature of changing needle moisture is effective for detecting bark beetle-induced tree mortality (e.g., Coops et al., 2010; Goodwin et al., 2008, Skakun et al., 2003; Walter and Platt, 2013). Maps like the one produced in this study that capture the range of outbreak severity can improve understanding of the ecological impacts of mountain pine beetles across landscapes, especially in areas lacking field measurements, since many of these impacts vary with outbreak severity.

\section{Conclusion}


Outbreak severity at Fraser Experimental Forest from the recent mountain pine beetle outbreak was assessed across a range of stand conditions and management histories. The most important predictor of mountain pine beetle outbreak severity was the amount of lodgepole pine basal area in a stand. Outbreak severity was modeled using BRT with field and Landsat 7 ETM+ data to compare outbreak severity between regenerating clearcut and mature forests. Stands harvested between 25 and 56 years before the end of the recent outbreak experienced lower levels of mortality than mature stands in Fraser Experimental Forest, although there was a large range in outbreak severities in young stands. Future work should use stand inventory data in regenerating clearcuts to better understand stand susceptibility in harvested stands and investigate how spatial configurations of young stands impact mortality at the landscape scale. The analysis of outbreak severity in past harvests is just one example of an analysis that is possible with a map of cumulative outbreak severity. Other applications include the study of forest regeneration, fire, timber harvest, carbon accounting and quantifying the impacts of forest disturbances on streamflow. More broadly, similar approaches can be utilized to assess the different vulnerabilities to disturbance arising from stand conditions and can contribute to strategic, spatially-explicit forest management planning that accounts for the diversity of ecological and social values associated with forests.

\section{Acknowledgements}

We would like to thank those involved in the development of this research. Renee Curry, Kelli Groy, Aaron Sidder, and William Zawacki contributed to the development of the models. Steve Chignell, Matthew Luizza, Tewodros Wakie, and Amanda West helped collect field data. Wayne Shepperd shared knowledge of forest management history at Fraser Experimental Forest. 
Our research was strengthened by conversations with Nicholas Young, Ryan Anderson, and John

Hogland. This work was supported by the Agriculture and Food Research Initiative Competitive

Grant [grant number 2013-68005-21298] from the USDA National Institute of Food and

Agriculture. Additional support provided by the NASA DEVELOP Program, the U.S.

Geological Survey Denver and Fort Collins Science Centers, the Colorado Forest Restoration

Institute, and the Natural Resource Ecology Laboratory at Colorado State University.

\section{References}

Alexander, R.A., Troendle, C.A., Kaufmann, M.R., Shepperd, W.D., Crouch, G.L., Watkins, R.K. 1985. The Fraser Experimental Forest, Colorado: Research Program and Published Research 1937-1985. USDA For. Serv., Rocky Mtn. For. and Range Exp. Stn., Gen. Tech. Rep. RM-118, 46 pp. Fort Collins, CO.

Alexander, R. R., 1987. Early history of St. Louis Creek and the Fraser Experimental Forest: A Narrative. USDA For. Serv., Rocky Mtn. For. and Range Exp. Stn., Gen. Tech. Rep. RM-149, 11 pp. Fort Collins, CO.

Amman, G.D., McGregor, M.D., Cahill, D.B., Klein, W.H., 1977. Guidelines for reducing losses of lodgepole pine to the mountain pine beetle in unmanaged stands in the Rocky Mountains, USDA For. Serv., Intermtn. For. Range Exp. Stn., Gen. Tech. Rep. INT-36, 19 pp. Ogden, UT.

Bartos, D.L., Ammman, G.D., 1989. Microclimate : An Alternative to Tree Vigor as a Basis for Mountain Pine Beetle Infestations. USDA For. Serv., Intermtn. For. Range Exp. Stn., Res. Pap. INT-400, $10 \mathrm{pp}$.

Bivand, R., Keitt, T., Rowlingson, B., 2015. rgdal: Bindings for the Geospatial Data Abstraction Library. R package version 1.1-3. https://CRAN.R-project.org/package=rgdal

Breiman L., Friedman J. H., Olshen R. A., Stone, C. J., 1984. Classification and Regression Trees. Wadsworth International Group, Belmont, CA, USA.

Bright, B.C., Hudak, A.T., Kennedy, R.E., Meddens, A.J.H., 2014. Landsat time series and lidar as predictors of live and dead basal area across five bark beetle-affected forests. IEEE J. Sel. Top. Appl. Earth Obs. Remote Sens. 7, 3440-3452. doi:10.1109/JSTARS.2014.2346955

Chapman, T.B., Veblen, T.T., Schoennagel, T., 2012. Spatiotemporal patterns of mountain pine beetle activity in the southern Rocky Mountains. Ecology 93, 2175-2185. doi:10.1890/11-1055.1 
Cohen, W.B., Goward, S.N., 2004. Landsat's Role in Ecological Applications of Remote Sensing. Bioscience 54, 535-545. doi:10.1641/0006-3568(2004)054[0535:LRIEAO]2.0.CO;2

Collins, B.J., Rhoades, C.C., Hubbard, R.M., Battaglia, M.A., 2011. Tree regeneration and future stand development after bark beetle infestation and harvesting in Colorado lodgepole pine stands. For. Ecol. Manage. 261, 2168-2175. doi:10.1016/j.foreco.2011.03.016

Collins, B.J., Rhoades, C.C., Underhill, J., Hubbard, R.M., 2010. Post-harvest seedling recruitment following mountain pine beetle infestation of Colorado lodgepole pine stands: a comparison using historic survey records. Can. J. For. Res. 40, 2452-2456. doi:10.1139/X10-172

Coops, N. C., Gillanders, S. N., Wulder, M. A., Gergel, S. E., Nelson, T., Goodwin, N. R., 2010. Assessing changes in forest fragmentation following infestation using time series Landsat imagery. For. Ecol. Manag. 259, 2355-2365. doi:10.1016/j.foreco.2010.03.008

Crist, E. P. Cicone, R. C., 1984. A physically-based transformation of Thematic Mapper dataThe TM Tasseled Cap. IEEE Transactions on Geosci. and Remote Sens. 22(3), 256-263. doi: 10.1109/TGRS.1984.350619

De'ath, G., 2007. Boosted regression trees for ecological modeling and prediction. Ecology 88, 243-251. doi:10.1890/0012-9658(2007)88[243:BTFEMA]2.0.CO;2

Dhar, A., Balliet, N., Runzer, K., Hawkins, C., 2015. Impact of a Mountain Pine Beetle Outbreak on Young Lodgepole Pine Stands in Central British Columbia. Forests 6, 3483-3500. doi:10.3390/f6103483

Diskin, M., Rocca, M.E., Nelson, K.N., Aoki, C.F., Romme, W.H., 2011. Forest developmental trajectories in mountain pine beetle disturbed forests of Rocky Mountain National Park, Colorado. Can. J. For. Res. 41, 782-792. doi:10.1139/x10-247

Dormann, C.F., Elith, J., Bacher, S., Buchmann, C., Carl, G., Carré, G., Marquéz, J.R.G., Gruber, B., Lafourcade, B., Leitão, P.J., Münkemüller, T., Mcclean, C., Osborne, P.E., Reineking, B., Schröder, B., Skidmore, A.K., Zurell, D., Lautenbach, S., 2013. Collinearity: A review of methods to deal with it and a simulation study evaluating their performance. Ecography. 36, 027-046. doi:10.1111/j.1600-0587.2012.07348.x

Edburg, S.L., Hicke, J.A., Brooks, P.D., Pendall, E.G., Ewers, B.E., Norton, U., Gochis, D., Gutmann, E.D., Meddens, A.J., 2012. Cascading impacts of bark beetle-caused tree mortality on coupled biogeophysical and biogeochemical processes. Front. Ecol. Environ. 10, 416-424. doi:10.1890/110173

Elith, J., Leathwick, J. R., Hastie, T., 2008. A working guide to boosted regression trees. J. Anim. Ecol. 77(4), 802-813. doi:10.1111/j.1365-2656.2008.01390.x

Environmental Systems Research Institute (ESRI), 2012. ArcGIS Desktop: Release 10.1. Redlands, CA. 
Exelis Visual Information Solutions, 2014. ENVI 5.1. Boulder, CO.

Fettig, C. J., Klepzig, K. D., Billings, R. F., Munson, A. S., Nebeker, T. E., Negrón, J. F., Nowak, J. T., 2007. The effectiveness of vegetation management practices for prevention and control of bark beetle infestations in coniferous forests of the western and southern United States. For. Ecol. Manag. 238, 24-53. doi:10.1016/j.foreco.2006.10.011

Friedman, J.H., 2001. Greedy Function Approximation: A Gradient Boosting Machine. Ann. Stat. 29, 1189-1232. doi:10.1214/aos/1013203451

Gesch, D., Oimoen, M., Greenlee, S., Nelson, C., Steuck, M., Tyler, D., 2002. The National Elevation Dataset. Photogramm. Eng. Remote Sens. 68(1), 5-11.

Gesch, D.B. 2007. The National Elevation Dataset, in Maune, D. (Ed.), Digital Elevation Model Technologies and Applications: The DEM User's Manual, second ed. Am. Soc. Photogramm. Remote Sens., Bethesda, Maryland. pp. 99-118.

Ghimire, B., Williams, C.A., Collatz, G.J., Vanderhoof, M., Rogan, J., Kulakowski, D., Masek, J.G., 2015. Large Carbon Release Legacy from Bark Beetle Outbreaks across Western United States. Glob. Chang. Biol. 21, 3087-3101. doi:10.1111/gcb.12933

Goodwin, N. R., Coops, N. C., Wulder, M. A., Gillanders, S., Schroeder, T. A., Nelson, T., 2008. Estimation of insect infestation dynamics using a temporal sequence of Landsat data. Remote Sens. Environ. 112(9), 3680-3689. doi:10.1016/j.rse.2008.05.005

Hansen, E.M., Amacher, M.C., Miegroet, H. Van, Long, J.N., Ryan, M.G., 2015. Carbon Dynamics in Central US Rockies Lodgepole Pine Type After Mountain Pine Beetle Outbreaks. For. Sci. 61, 1-15. doi:10.5849/forsci.14-094

Hijmans, R.J., 2015. raster: Geographic Data Analysis and Modeling. R package version 2.5-2. https://CRAN.R-project.org/package=raster

Huang, C., Wylie, B., Yang, L., Homer, C., Zylstra, G., 2002. Derivation of a tasselled cap transformation based on Landsat 7 at-satellite reflectance. Int. J. Remote Sens. 23(8), 1741-1748. doi:10.1080/01431160110106113

Hubbard, R. M., Rhoades, C. C., Elder, K., Negron, J., 2013. Changes in transpiration and foliage growth in lodgepole pine trees following mountain pine beetle attack and mechanical girdling. For. Ecol. Manag. 289, 312-317. doi:10.1016/j.foreco.2012.09.028

Huckaby, L.S., Moir, W.H., 1998. Forest Communities at Fraser Experimental Forest, Colorado. Southwest. Nat. 43, 204-218. doi:10.1894/0038-4909-55.2.310 
Johnson, T.N., Buskirk, S.W., Hayward, G.D., Raphael, M.G., 2014. Tree mortality after synchronized forest insect outbreaks: Effects of tree species, bole diameter, and cutting history. For. Ecol. Manage. 319, 10-17. doi:10.1016/j.foreco.2014.01.047

Johnson, T.N., Buskirk, S.W., Hayward, G.D., Raphael, M.G., 2015. Timber harvest interacts with broad-scale forest mortality to affect site occupancy dynamics of a vertebrate seed predator. For. Ecol. Manage. 340, 95-102. doi:10.1016/j.foreco.2014.12.030

Kaiser, K.E., Mcglynn, B.L., Emanuel, R.E., 2013. Ecohydrology of an outbreak: Mountain pine beetle impacts trees in drier landscape positions first. Ecohydrology 6, 444-454. doi:10.1002/eco.1286

Klutsch, J.G., Negrón, J.F., Costello, S.L., Rhoades, C.C., West, D.R., Popp, J., Caissie, R., 2009. Stand characteristics and downed woody debris accumulations associated with a mountain pine beetle (Dendroctonus ponderosae Hopkins) outbreak in Colorado. For. Ecol. Manage. 258, 641-649. doi:10.1016/j.foreco.2009.04.034

Kumar, S., Stohlgren, T. J., Chong, G. W., 2006. Spatial heterogeneity influences native and nonnative plant species richness. Ecol. 87(12), 3186-3199. doi:10.1890/00129658(2006)87[3186:SHINAN]2.0.CO;2

Leutner, B., Horning, N., 2015. RStoolbox: Tools for Remote Sensing Data Analysis. R package version 0.1.3. https://CRAN.R-project.org/package=RStoolbox

Long, J.A., Lawrence, R.L., 2016. Mapping Percent Tree Mortality Due to Mountain Pine Beetle Damage. For. Sci. 62, 1-11. doi:10.5849/forsci.15-046

Maclauchlan, L., 2006. Status of mountain pine beetle attack in young lodgepole pine stands in central British Columbia, Report to the Chief Forester Health Review Committee Meeting, Victoria, BC.

Maclauchlan, L.E., Brooks, J.E., White, K.J., 2015. Impacts and Susceptibility of Young Pine Stands to the Mountain Pine Beetle, Dendroctonus ponderosae, in British Columbia. J. Ecosyst. Manag. 15, 1-18.

Masek, J.G., Vermote, E.F., Saleous, N.E., Wolfe, R., Hall, F.G., Huemmrich, K.F., Gao, F., Kutler, J., Lim, T., 2006. A Landsat Surface Reflectance Dataset. IEEE Geosci. Remote Sens. Lett. 3, 68-72. doi:10.1109/LGRS.2005.857030

Meddens, A. J., Hicke, J. A., 2014. Spatial and temporal patterns of Landsat-based detection of tree mortality caused by a mountain pine beetle outbreak in Colorado, USA. For. Ecol. Manag. 322, 78-88. doi:10.1016/j.foreco.2014.02.037

Nelson, K.N., Rocca, M.E., Diskin, M., Aoki, C.F., Romme, W.H., 2014. Predictors of bark beetle activity and scale-dependent spatial heterogeneity change during the course of an outbreak in a subalpine forest. Landsc. Ecol. 29, 97-109. doi:10.1007/s10980-013-9954-1 
Pfeifer, E.M., Hicke, J. a., Meddens, A.J.H., 2011. Observations and modeling of aboveground tree carbon stocks and fluxes following a bark beetle outbreak in the western United States. Glob. Chang. Biol. 17, 339-350. doi:10.1111/j.1365-2486.2010.02226.x

Popovich, S.J., Shepperd, W.D., Reichert, D.W., Cone, M.A., 1993. Flora of the Fraser Experimental Forest, Colorado. USDA For. Serv., Rocky Mtn. For. and Range Exp. Stn., Gen. Tech. Rep. RM-233, 68 pp. Fort Collins, CO.

Pugh, E., Small, E., 2012. The impact of pine beetle infestation on snow accumulation and melt in the headwaters of the Colorado River. Ecohydrology 5, 467-477. doi:10.1002/eco.239

R Core Team, 2015. R: a language and environment for statistical computing. $\mathrm{R}$ foundation for statistical computing, Vienna, Austria. URL https:/www.R-project.org/.

Rhoades, C.C., McCutchen, Jr., J.H., Cooper, L.A., Clow, D.W., Detmer, T.M., Briggs, J.S., Stednick, J.D., Veblen, T.T., Ertz, R.M., Likens, G., Lewis , Jr., W.M., 2013. Biogeochemistry of Beetle Kill: Explaining a weak nitrate response. Proc. Natl. Acad. Sci. 110(5), 1756-1760. doi: 10.1073/pnas.1221029110

Rhoades, C.C, Hubbard, R.M., Elder, K., 2016. A decade of streamwater nitrogen and forest dynamics after a mountain pine beetle outbreak at the Fraser Experimental Forest, Colorado. Ecosystems, 1-13. doi:10.1007/s10021-016-0027-6

Riaño, D., Chuvieco, E., Salas, J., Aguado, I., 2003. Assessment of different topographic corrections in Landsat-TM data for mapping vegetation types. Geosci. Remote Sens., IEEE Trans. 41, 1056-1061. doi:10.1109/TGRS.2003.811693

Ridgeway, G., with contributions from others, 2015. gbm: Generalized Boosted Regression Models. R package version 2.1.1. https://CRAN.R-project.org/package=gbm

Robinson, A., 2015. equivalence: Provides Tests and Graphics for Assessing Tests of Equivalence. R package version 0.7.0. https://CRAN.R-project.org/package=equivalence

Safranyik, L., Carroll, A.L., 2006. The biology and epidemiology of the mountain pine beetle in lodgepole pine forests, in: Safranyik, L., Wilson, B. (Eds.) The Mountain Pine Beetle: A Synthesis of Biology, Mangement, and Impacts on Lodgepole Pine. Nat. Resour. Can., Can. For. Serv., Pac. For. Cent., pp 3-66. Victoria, BC.

Savage, S.L., Lawrence, R.L., Squires, J.R., 2015. Predicting relative species composition within mixed conifer forest pixels using zero-inflated models and Landsat imagery. Remote Sens. Environ. 171, 326-336. doi:10.1016/j.rse.2015.10.013

Shore, T., Safranyik, L., 1992. Susceptibility and risk rating systems for the mountain pine beetle in lodgepole pine stands. Forestry Canada, Pacific Forestry Centre, Information Report BC-X336, 12 pp. Victoria, BC. 
Shrimpton, D.M., 1973. Age- and size-related response of lodgepole pine to inoculation with Europhium clavigerum. Can. J. Bot. 51, 1155-1160. doi:10.1139/b73-146

Sidder, A.M., Kumar, S., Laituri, M., Sibold, J.S., 2016. Using spatiotemporal correlative niche models for evaluating the effects of climate change on mountain pine beetle. Ecography. 7, 1-22. doi:e01396. 10.1002/ecs2.1396

Simard, M., Powell, E.N., Raffa, K.F., Turner, M.G., 2012. What explains landscape patterns of tree mortality caused by bark beetle outbreaks in Greater Yellowstone? Glob. Ecol. Biogeogr. 21, 556-567. doi:10.1111/j.1466-8238.2011.00710.x

Skakun, R.S., Wulder, M.A., Franklin, S.E., 2003. Sensitivity of the thematic mapper enhanced wetness difference index to detect mountain pine beetle red-attack damage. Remote Sens. Environ. 86, 433-443. doi:10.1016/S0034-4257(03)00112-3

Therneau T.M., Atkinson E.J., 2011. An introduction to recursive partitioning using the RPART routines. Mayo Clinic, Rochester, MN.

Therneau, T., Atkinson, B., Ripley, B., 2015. rpart: Recursive Partitioning and Regression Trees. $\mathrm{R}$ package version 4.1-10. https://CRAN.R-project.org/package=rpart

Tishmack, J., Mata, S.A., Schmid, J.M.., 2005. Mountain Pine Beetle Emergence From Lodgepole Pine at Different Elevations Near Fraser, CO. USDA For. Serv., Rocky Mtn. Res. Stn., Res. Note RMRS-RN-27, 5 pp. Fort Collins, CO.

Troendle, C.A., King, R.M., 1985. The Effect of Timber Harvest on the Fool Creek Watershed, 30 Years Later. Water Resour. Res. 21(12), 1915-1922. doi: 10.1029/WR021i012p01915

USDA Farm Service Agency. National Agriculture Imagery Program. Salt Lake City, UT. Retrieved from http://datagateway.nrcs.usda.gov/

USDA Forest Service, 2013. Forest Insect and Disease Aerial Survey Data, Rocky Mountain Region. Retrieved from http://www.fs.fed.us/r2/resources/fhm/aerialsurvey/download/ (accessed October 1, 2013).

USGS EROS Data Center. National Aerial Photography Program. Sioux Falls, SD. Retrieved from http://earthexplorer.usgs.gov/

Vanonckelen, S., Lhermitte, S., Van Rompaey, A., 2013. The effect of atmospheric and topographic correction methods on land cover classification accuracy. Int. J. Appl. Earth Obs. Geoinf. 24, 9-21. doi:10.1016/j.jag.2013.02.003

Walter, J.A., Platt, R. V., 2013. Multi-temporal analysis reveals that predictors of mountain pine beetle infestation change during outbreak cycles. For. Ecol. Manage. 302, 308-318.

doi:10.1016/j.foreco.2013.03.038 
Wulder, M.A., White, J.C., Bentz, B., Alvarez, M.F., Coops, N.C., 2006. Estimating the probability of mountain pine beetle red-attack damage. Remote Sens. Environ. 101, 150-166. doi:10.1016/j.rse.2005.12.010

Wulder, M. A., Masek, J.G., Cohen, W.B., Loveland, T.R., Woodcock, C.E., 2012. Opening the archive: How free data has enabled the science and monitoring promise of Landsat. Remote Sens. Environ. 122, 2-10. doi:10.1016/j.rse.2012.01.010 